\title{
Stability of Surface-Immobilized Lubricant Interfaces under Flow
}

\section{Citation}

Howell, Caitlin, Thy L. Vu, Christopher P. Johnson, Xu Hou, Onye Ahanotu, Jack Alvarenga, Daniel C. Leslie, et al. 2015. Stability of Surface-Immobilized Lubricant Interfaces Under Flow. Chem. Mater. 27, no. 5: 1792-1800. doi:10.1021/cm504652g.

\section{Published Version}

doi:10.1021/cm504652g

\section{Permanent link}

http://nrs.harvard.edu/urn-3:HUL.InstRepos:27663227

\section{Terms of Use}

This article was downloaded from Harvard University's DASH repository, and is made available under the terms and conditions applicable to Open Access Policy Articles, as set forth at http:// nrs.harvard.edu/urn-3:HUL.InstRepos:dash.current.terms-of-use\#OAP

\section{Share Your Story}

The Harvard community has made this article openly available.

Please share how this access benefits you. Submit a story.

Accessibility 


\title{
Stability of Surface-Immobilized Lubricant Interfaces Under Flow
}

\author{
Caitlin Howell, ${ }^{\text {ab* }}{ }^{*}$ Thy L. Vu, ${ }^{\text {a }}$ Christopher P. Johnson, ${ }^{a}$ Xu Hou, ${ }^{\text {ab }}$ Onye Ahanotu, ${ }^{\text {a }}$ Jack Al- \\ varenga, ${ }^{a}$ Daniel C. Leslie, ${ }^{\text {abc }}$ Oktay Uzun, ${ }^{\mathrm{a}}$ Anna Waterhouse, ${ }^{\text {ad }}$ Philseok Kim, ${ }^{\mathrm{a}}$ Michael Su- \\ per, ${ }^{\text {acd }}$ Michael Aizenberg, ${ }^{\text {a }}$ Donald E. Ingber, ${ }^{\text {abcd }}$ and Joanna Aizenbergabe*
}

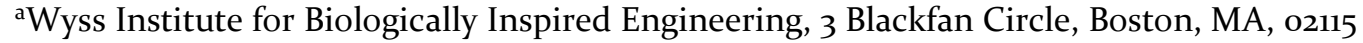 \\ bschool of Engineering and Applied Sciences, Harvard University, 9 Oxford Street, Cambridge, MA, o2138 \\ 'Vascular Biology Program, Departments of Pathology and Surgery, Boston Children's Hospital, Boston, MA 02115 \\ ${ }^{\mathrm{d}}$ Harvard Medical School, Boston, MA 02115 \\ eDepartment of Chemistry and Chemical Biology and Kavli Institute for Bionano Science and Technology, Harvard \\ University, 12 Oxford Street, Cambridge, Massachusetts 02138
}

\begin{abstract}
The stability and longevity of surface-stabilized lubricant layers is a critical question in their application as low- and non-fouling slippery surface treatments in both industry and medicine. Here, we investigate lubricant loss from surfaces under flow in water using both quantitative analysis and visualization, testing the effects of underlying surface type (nanostructured versus flat), as well as flow rate in the physiologically-relevant range, lubricant type, and time. We find lubricant losses on the order of only $\mathrm{ng} / \mathrm{cm}^{2}$ in a closed system, indicating that these interfaces are relatively stable under the flow conditions tested. No notable differences emerged between surface type, flow rate, lubricant type, or time. However, exposure of the lubricant layers to an air/water interface did significantly increase the amount of lubricant removed from the surface, leading to disruption of the layer. These results may help in the development and design of materials using surface-immobilized lubricant interfaces for repellency under flow conditions.
\end{abstract}

\section{INTRODUCTION}

The use of surface-immobilized liquid interfaces as pressure-stable, omniphobic surfaces has recently emerged as a way of fabricating a highly adaptable new class of non-stick materials for industry and medicine. ${ }^{1}$ Originally inspired by the Nepenthes pitcher plant and termed SLIPS (short for Slippery Liquid Infused Porous Surfaces), these coatings have been shown to be effective against adhesion of a wide range of substances including crude oil, ${ }^{1}$ blood, ${ }^{1,2}$ ice, ${ }^{3}$ and bacterial biofilms ${ }^{2,4,5,6,7}$, as well as in marine environments. ${ }^{8,9}$ Furthermore, the relatively simple concept on which they are based - that the liquid must have a greater affinity for the surface than the substance being repelled ${ }^{1}$ - provides significant flexibility. This allows surface-immobilized liquid layers to be fabricated on several different types of substrates including aluminum, ${ }^{3}$ glass, ${ }^{2,3,10,11}$ and multiple types of plastics, ${ }^{3,2}$ as well as on state-of-the-art tunable polymeric materials. ${ }^{2,12}$

The foundation of this technology is the presence of the surface-stabilized liquid overlayer, which provides a low-adhesion interface that prevents the permanent attachment of fouling materials and, in the case of damage, can self-heal. This is in stark contrast to other solid material-based non-stick technologies, which frequently make use of either chemical methods, such as surface functionalization with low-fouling molecular species ${ }^{13,14,15}$ or physical methods such as air trapped between nanostructures $^{16,17,18,19,20}$ to produce a repellent effect, which is how- ever very limited due to the inherent stickiness that can be a property of exposed solid surfaces. ${ }^{21}$

For practical applications, it is important to consider the stability and longevity of immobilized liquid layers as surf ace coatings, especially under flow conditions. Liquid alone is, by its nature, a highly mobile phase of matter prone to change with relatively minimal input from external forces. The stability of liquid/liquid interfaces under flow has received some attention in the petroleum industry in the form of investigations into the effectiveness of core-annular flow as a method of reducing friction in pipes. ${ }^{22,23,24}$ Although an increased relative flow rate between the water and oil phases in these systems (resulting in turbulent rather than laminar flow) increased the instability of the interface, both mathematical modeling and experimental evidence showed that the proximity of the tube wall dampened this effect, stabilizing both the oil and water layers. Furthermore, this macroscale stabilization effect appeared to be more pronounced the closer the wall was to the liquid/liquid interface. ${ }^{22,24}$ Studies of this type usually take place on the scale of centimeters to millimeters; however the types of liquid interfaces used for omniphobic surface coatings are generally on the order of micrometers to nanometers from the solid surface to which they are bound, ${ }^{1,25,26}$ which may increase the stabilization effect.

Previous reports on the stability of surface-bound liquid layers under static conditions have focused on the behavior of individual droplets of test liquids, primarily 
water, interacting with these surfaces., ${ }^{1,26,27,28}$ These investigations have shown the surface-immobilized liquid layer to remain stable upon introduction of the droplets; however, the appearance of a thin cloaking or wrapping layer of lubricant covering the droplets has been sometimes observed. ${ }^{26,27}$ The origin of this wrapping layer has been ascribed to the differences in surface energy between the surface-immobilized liquid, the liquid being repelled (water), and the air: the low surface energy of the lubricant makes a lubricant-air interface more energetically favorable than an air/water interface. The result is formation of a thin layer of lubricant over the droplet upon introduction of the droplet to the surface. ${ }^{26,27}$ Nevertheless, the amount of lubricant necessary to cover the droplet has generally not appeared to be enough to noticeably disrupt the underlying lubricant layer.

Yet a thorough investigation of the stability of lubricant/liquid interfaces under flow is still required, as this is directly relevant to the ways such surfaces would be used in many industrial and medical applications. Here, we begin addressing this question by quantifying lubricant loss from surfaces under flowing water using both analytical and visual methods. We examine lubricant layers of two different viscosities immobilized on both flat and structured surfaces of similar chemistries under physiologically relevant flow conditions.

We find that after an initial conditioning step in which any excess lubricant is removed from the surface, further loss in a closed-loop system is minimal as determined by our methods. Furthermore, the amount of lubricant removed from the surface does not differ significantly between chemically functionalized flat and structured surfaces, nor between the two different viscosities tested over multiple flow rates and time points up to 16 hours. However, the lower viscosity lubricant does appear to be more mobile on the surface. Finally, we find that the most disruptive force to the lubricant layer is the passage of the air/water interface, which appears to peel a significant amount of the lubricant from the surface. These results help to answer questions about the stability of these layers under flow, specifically in closed systems, which will aid in their further development for medical and industrial applications.

\section{EXPERIMENTAL SECTION}

2.1 Macroscale lubricant loss. Investigations of lubricant loss on the macroscale were performed by attaching sections of medical-grade, polyvinyl chloride (PVC) tubing to a peristaltic pump and allowing water to flow through the tubing for defined periods of time. Two types of fluorinated surfaces were created on the interior of the tubing: one with alumina sol-gel-based nanoscale structures functionalized with perfluoroalkyl phosphate surfactant $^{25}$ (henceforth structured surfaces), and another with just the tubing surface itself functionalized with tridecafluoro-1,1,2,2-tetrahydrooctyl trichlorosilane ${ }^{2}$ (henceforth flat surfaces). Details on the fabrications of these surfaces are below.
2.1.1 Tubing interior surface treatments. Flat and structured fluorinated surfaces were fabricated on the insides of Tygon or Sorin PVC tubing as outlined in the Supplementary Information. The surfaces were visualized using a Zeiss Supra Field Emission Scanning Electron Microscope (Carl Zeiss, Oberkochen, Germany) to ensure either the presence (for the structured surfaces) or absense (for the flat surfaces) of nanoscale topography (Figure 1). All surfaces were also analyzed using a Thermo Scientific K-alpha X-ray photoelectron spectrometer (XPS) to confirm the presence of the fluorine functionalization (Supplementary Information Figure S1).
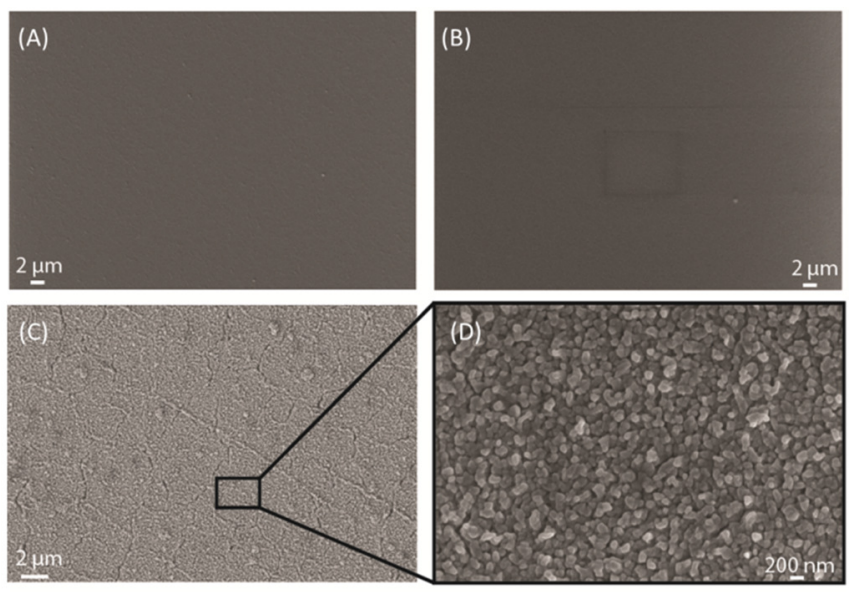

Figure 1. SEM images of the interior surface of untreated PVC tubing (A), flat fluorinated surface created inside the tubing $(B)$, and a nanostructured fluorinated surface created on the inside of the tubing $(C)$ and its magnified view (D).

2.1.2 Pump setup and surface lubrication. A flow setup with a peristaltic pump was assembled according to Figure 2. Silicone peristaltic pump tubing with an inner diameter of $1 / 4$ " (McMaster-Carr, Robbinsville, NJ) running through the pump heads was first thoroughly cleaned by pumping through de-ionized, distilled water for $5 \mathrm{~min}$ in an open loop, followed by rinsing with hydrofluoroether Novec HFE 7100 solvent (3M, St. Paul, MN) to remove any residuals, followed again by DIW for $20 \mathrm{~min}$. Untreated silicone tubing (rather than lubricant-coated tubing) was used to run through the peristaltic pump heads in order to eliminate any artifacts that may have been caused by the mechanical deformation of the tubing and coating by the pump rollers.

Immediately prior to measurements, $8-\mathrm{cm}$ pieces of the PVC tubing with either fluoro-functionalized flat or structured interior surfaces were treated with one of two different types of perfluorinated lubricant: Krytox 103 perfluoropolyether (DuPont, Wilmington, DE) or perfluorodecalin (PFD) (Sigma-Aldrich, St. Louis, MO). Krytox was chosen as its chemical inertness, general immiscibility, and high wettability in fluorinated porous substrates have made it highly useful for industriallyrelevant applications., ${ }^{1,32}$ PFD, in contrast, has been viewed as an appropriate lubricant for SLIPS due to its 
previous application as a component of blood substitutes ${ }^{30,31}$ as well the material aiding in vitreoretinal surgeries, ${ }^{32,33}$ making this lubricant a desirable candidate for medical applications. ${ }^{2}$

Lubricant was added in excess, then allowed to drain out for approximately 5 min for Krytox, or approximately 1 min for PFD (due to its lower viscosity and higher evaporation rate). Nylon barbed luer locks and caps (McMaster-Carr, Robbinsville, NJ) were then added to the ends of the tubing to prevent further lubricant loss through drainage or evaporation. Weights were measured before and after lubricant addition to calculate the amount of lubricant remaining on the tubing interior surfaces.

The 8-cm pieces of the treated tubing were then connected to one end of the silicone tubing running through the peristaltic pump. Fresh DIW was pumped through one end of the system and allowed to flow over the treated tubing continuously for $20 \mathrm{~min}$ at $10 \mathrm{~mL} / \mathrm{min}$ to remove excess lubricant. Following this step, the treated tubing was connected to the end of the silicone tubing to form a closed loop (Figure $2 \mathrm{~A}$ ). Water was then pumped in the closed loop at 10,50 or $90 \mathrm{~mL} / \mathrm{min}$, chosen as flow rates representative of those used in applications such as neonatal haemodialysis 34 and concentrated ascites reinfusion therapy. ${ }^{35}$ All flow experiments were performed simultaneously in triplicate using a triple peristaltic pump head. Water aliquots of approximately $10 \mathrm{~mL}$ were collected for analysis by Gas Chromatography-Mass Spectrometry (GC-MS) after 2, 4, and 16 h of continuous flow through the closed loop. The water sampling was then followed by complete refilling of the loops with fresh water before being further subjected to continuous flow in a closed loop for the next time point. Samples were collected while taking great care not to pass any air/water interfaces over the treated tubing surfaces until after the final $16 \mathrm{~h}$ time point.

2.1.3 Lubricant Extraction. Collected water aliquots were spiked with $4 \mu \mathrm{L}$ of a perflubron internal standard (64 $\mu \mathrm{g} / \mathrm{g}$ ) (Sigma-Aldrich, St. Louis, MO), followed by 1 $\mathrm{mL}$ of HFE 7100 as the extracting solvent. The two were mixed vigorously for $10 \mathrm{~min}$ and centrifuged for $10 \mathrm{~min}$ at $4000 \mathrm{rpm}$. The bottom HFE fraction was then removed for analysis either by GC-MS (for PFD) or Gas Chromatography with an Electron Capture Detector (GC-ECD) (for Krytox 103).

2.1.4 Gas chromatography analysis. The detection of PFD was done using an HP 7890/5975 GC-MS system (Hewlett-Packard, Palo Alto, CA). The chromatographic separation was performed by injection in the pulsed splitless mode of $5 \mu \mathrm{L}$ of the HFE extract containing PFD and perflubron into a $\mathrm{HP}-5 \mathrm{MS}$ capillary column having $5 \%$ phenyl $/ 95 \%$ methyl siloxane as the stationary phase (length: $30 \mathrm{~m}$; I.D. $0.25 \mathrm{~mm}$; film thickness: $0.25 \mu \mathrm{m})(\mathrm{Ag}-$ ilent Technologies, Santa Clara, CA). Helium pressure was $10 \mathrm{psi}$. The injector temperature was $200^{\circ} \mathrm{C}$ and the initial oven temperature was $35^{\circ} \mathrm{C}$. After injection, the oven temperature was raised to $50^{\circ} \mathrm{C}$ at $4.8^{\circ} \mathrm{C} / \mathrm{min}$ and held for $0.5 \mathrm{~min}$. Then, the column temperature was heated at $82^{\circ} \mathrm{C} / \mathrm{min}$ to $250^{\circ} \mathrm{C}$ and held for $6 \mathrm{~min}$. The transfer line temperature was set to $250^{\circ} \mathrm{C}$. Analysis was performed by electron impact ionization-quadrupole mass spectrometry. The ion source temperature was set to $230^{\circ} \mathrm{C}$. The electron energy was $70 \mathrm{eV}$. PFD and perflubron were analyzed in SIM mode. Two selected ions were recorded for each compound: ions $\mathrm{m} / \mathrm{z} 293\left(\mathrm{C}_{6} \mathrm{~F}_{10}\right)^{+}$and $\mathrm{m} / \mathrm{z} 243\left(\mathrm{C}_{5} \mathrm{~F}_{8}\right)^{+}$ specifically for PFD, and ions $\mathrm{m} / \mathrm{z} 419\left(\mathrm{C}_{8} \mathrm{~F}_{17}\right)^{+}$and $\mathrm{m} / \mathrm{z} 331$ $\left(\mathrm{C}_{5} \mathrm{~F}_{10} \mathrm{Br}\right)^{+}$specifically for perflubron. 

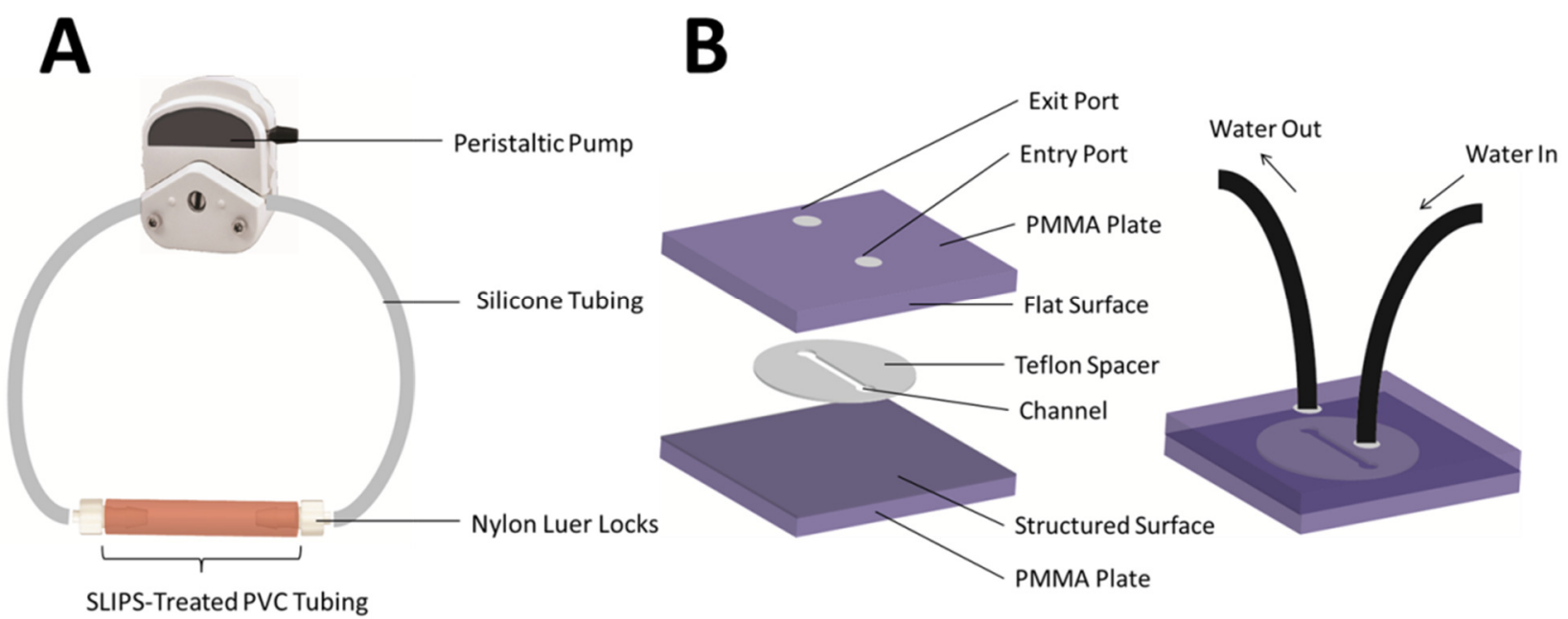

Figure 2. (A) Diagram of the macroscale peristaltic flow experimental setup. (B) Diagram of the mesoscale experimental setup used for the visualization experiments.

The detection of Krytox 103 was done using the same HP 7890 GC system but with an electron capture detector (GC-ECD) for analysis. The chromatographic separation was performed by injection in the pulsed splitless mode of $5 \mu \mathrm{L}$ of the HFE extract containing $\mathrm{K}_{10}$ and perflubron into an HP-1MS capillary column having $100 \%$ dimethylpolysiloxane as the stationary phase (length: $30 \mathrm{~m}$; I.D. $0.25 \mathrm{~mm}$; film thickness: $0.25 \mu \mathrm{m}$ ) (Agilent Technologies, Santa Clara, CA). Helium pressure was 10 psi. The injector temperature was $325^{\circ} \mathrm{C}$ and the initial oven temperature was $35^{\circ} \mathrm{C}$. After injection, the oven temperature was raised to $50^{\circ} \mathrm{C}$ at $4.8^{\circ} \mathrm{C} / \mathrm{min}$ and held for $0.5 \mathrm{~min}$. Then, the column temperature was heated at $82^{\circ} \mathrm{C} / \mathrm{min}$ to $250^{\circ} \mathrm{C}$ and held for $6 \mathrm{~min}$. The oven temperature was then increased to $325^{\circ} \mathrm{C}$ at a rate of $99^{\circ} \mathrm{C} / \mathrm{min}$ and held for 2.18 $\mathrm{min}$. The total run time was $15 \mathrm{~min}$. The electron capture detector was operated at $300^{\circ} \mathrm{C}$ while maintaining a nitrogen makeup flow of $10.85 \mathrm{~mL} / \mathrm{min}$.

Quantitation of lubricant concentration for both PFD and Krytox 103 was done using ChemStation Enhanced Data Analysis with the ChemStation or RTE integrator (Agilent Technologies, Santa Clara, CA), with perflubron serving as the internal standard. Each sample run included a blank solvent injection with HFE 7100 for every three sample injections as well as a $0.064 \mu \mathrm{g} / \mathrm{g}$ PFD standard to monitor instrument stability.

2.2 Mesoscale Lubricant Loss. Mesofluidic channels with flat and structured fluorinated surfaces were prepared in order to visualize lubricant loss and provide confirmation of the results found using the peristaltic pump and treated tubing. Briefly, a VersaLaser engraving system (Universal Laser Systems, Dade City, FL) was used to cut a channel approximately $1 \mathrm{~mm}$ wide into an expanded polytetrafluoroethylene (ePTFE) membrane $(5 \mu \mathrm{m}$ porosity, Sterlitech Co., Kent, WA). This membrane was then sandwiched between two transparent PMMA sheets (Figure $2 \mathrm{~B}$ ), resulting in a fully enclosed mesofluidic channel with dimensions of approximately $1 \mathrm{~mm} \times 15 \mathrm{~mm} \times 0.2$ $\mathrm{mm}$.
2.2.1 Surface treatment of the mesofluidic devices. In order to create the structured and flat fluorinated surfaces used in the mesoscale lubricant loss experiments, the two PMMA sheets enclosing the ePTFE spacer were functionalized with either a similar nanostructured, fluorinated surface or simply fluorinated surface. SEM analysis of the surfaces post-treatment showed structures similar to those observed for the treated tubing.

To create the nanostructured surface on a PMMA plate, a sol-gel method involving acetoacetate-stabilized aluminum tri-sec-butoxide solution in a mixture of isopropyl alcohol and water was adopted. ${ }^{25}$ Prior to application, the underlying acrylic substrate was activated using oxygen plasma (250W for 5 min in a Plasma Etch PE-200) to promote adhesion. The sol-gel solution was then spread uniformly across the substrate surface via spincoating to achieve an alumina layer measuring approximately $1 \mu \mathrm{m}$ in thickness. Following a $1 \mathrm{~h}$ curing at $70^{\circ} \mathrm{C}$, the substrates were immersed in $70^{\circ} \mathrm{C}$ DIW for 10 min to convert the alumina surface into a layer of boehmite. ${ }^{29}$ These structured surfaces were then fluorinated using an inductively-coupled $\mathrm{C}_{4} \mathrm{~F}_{8}$ plasma $(600 \mathrm{~W}$ for $8 \mathrm{~s}$ in a Surface Technology Systems Inductively Coupled PlasmaReactive Ion Etching system).

The flat fluorinated surfaces were fabricated by directly fluorinating the PMMA using the same inductivelycoupled $\mathrm{C}_{4} \mathrm{~F}_{8}$ plasma method. The resulting devices were assembled such that each had one structured fluorinated surface and one flat fluorinated surface to allow for the direct comparison of the two surface treatments in a single experiment.

2.2.2 Mesofluidic flow device lubrication. Directly prior to device assembly and measurement, the ePTFE spacer containing the channel was soaked with either fluorescently labeled Krytox 103 or fluorescently labeled PFD. Both lubricants were labeled using $\sim 70 \mathrm{~nm}$ calcium carbonate nanoparticles with surface carboxyl groups (Minerals Technologies, Inc., Bethlehem, PA) ionically coupled to rhodamine B fluorophores. 
Briefly, the fluorescently labeled lubricants were fabricated by first mixing the nanoparticles with a solution of rhodamine B overnight, resulting in an ionic attachment of the fluorophores. This was followed by a liquid-liquid extraction by vigorously shaking the mixture with a carboxyl terminated Krytox 157 FSL diluted 1:5 in HFE 7100 specialty liquid until a pink color appeared in the oil phase. The oil phase was then diluted approximately 1:10 in either Krytox 103 or PFD for the experiments.

After addition of the lubricants to the spacer and securing of the top and bottom surface-treated PMMA pieces, water was pumped through the channel at a rate of 100 $\mu \mathrm{L} / \mathrm{min}$ for 5 min using a syringe pump (Harvard Apparatus, Holliston, MA) to remove excess lubricant. The pump was then run for 5 min each at flow rates of 100, 200, 400, 800, and $1600 \mu \mathrm{L} / \mathrm{min}$. Using a Zeiss Confocal Laser Scanning Microscope (LSM 70o, Carl Zeiss Microscopy GmbH, Jena, Germany) a confocal stack was taken at the end of each interval to assess the amount of fluorescent signal remaining on the structured and flat surfaces. Finally, the flow rate was returned to $100 \mu \mathrm{L} / \mathrm{min}$ and an air/water interface was passed through the channel.

Confocal images were analyzed using ImageJ software with the microscopy package from the McMaster Biophotonics Facility. All images were thresholded and quantified for mean intensity of the fluorescent signal as an indication of the amount of lubricant remaining on the surfaces.

2.3 Statistics. All statistical analyses were performed using IBM SPSS Statistics version 20 (IBM, Armonk, NY). Univariate analysis of variance (ANOVA) was used with lubricant loss as the dependent factor and surface type, flow rate, lubricant type, and time as the independent factors ${ }^{36}$.

\section{RESULTS AND DISCUSSION}

3.1 Macroscale Quantification. Gravimetric analysis and sliding angle measurement showed that both the flat and structured functionalized tubing retained their lubricant layers after $16 \mathrm{~h}$ under continuous flow. Treated tubing coated with Krytox 103 and drained of excess lubricant before flow contained $0.05 \mathrm{~g}( \pm 0.01 \mathrm{~g})$ and $0.04 \mathrm{~g}( \pm 0.01 \mathrm{~g})$ of retained Krytox 103 for the structured and the flat surfaces, respectively. Untreated control tubing lubricated in an identical manner showed retention values of $0.003 \mathrm{~g}$ $( \pm 0.002 \mathrm{~g})$, confirming that little to no lubricant remained on these surfaces even before flow. Gravimetric analysis of structured, flat, and control samples after $16 \mathrm{~h}$ of flow showed no detectable change in these values. Sliding angles for a $70 \mu \mathrm{L}$ water drop on the lubricated structured tubing were below $5^{\circ}$ both before and after flow. Sliding angles for the flat tubing were at or under $5^{\circ}$ before flow, but were found to be an average of $12^{\circ} \pm 6^{\circ}$ after flow; the large error indicating areas of non-uniform lubricant loss. Sliding angles for untreated controls after the same treatment were found to be $24^{\circ} \pm 2^{\circ}$ both before and after flow.

GC-ECD analysis of the water pumped over the surfaces showed very little loss of the lubricant from either surface type after 2, 4, and $16 \mathrm{~h}$ of flow. Figure 3 shows the amount of Krytox 103 per $\mathrm{cm}^{2}$ of the inner surface of the tubes present in the water at these time points for the three flow rates tested $(10,50$, and $90 \mathrm{~mL} / \mathrm{min})$. The average solubility of Krytox 103 in water under static conditions after $16 \mathrm{~h}$ was found to be approximately $52 \mathrm{ng} / \mathrm{cm}^{2}$ $\left( \pm 46 \mathrm{ng} / \mathrm{cm}^{2}\right)$ (see Figure $\mathrm{S}_{2}$ in the Supplemental Information for details). Although the values for the amount of lubricant in the water at times appeared higher, especially for the flat surfaces, and the variability increased considerably, the amount of lubricant detected under all conditions stayed in the $\mathrm{ng} / \mathrm{cm}^{2}$ range. A univariate ANOVA revealed no significant differences in Krytox 103 concentrations among the flow rates or time points for either surface type under flow $(\mathrm{P}=0.267)$, or between the surfaces under flow and under static conditions $(\mathrm{P}=$ 0.508 ).

These results suggests that the 20 min conditioning step at $10 \mathrm{~mL} / \mathrm{min}$ was enough to stabilize the immobilized liquid on both surface types, which then remained stable at all three of the flow rates tested over $16 \mathrm{~h}$. If all of the tubing sections were completely stripped of lubricant, we would expect to see measured values solidly in the $\mu \mathrm{g} / \mathrm{cm}^{2}$ range, about $2-3$ orders of magnitude higher. The fact that this is not observed suggests that the lubricant remains on the surface, in agreement with the sliding angle data that show little to no change and after flow.

3.2 Mesoscale Visualization. Visual analysis of similar surface types (structured and flat) under flow in a mesofluidic channel confirmed the GC-MS and GC-ECD results. Figure $4 \mathrm{~A}$ shows a top-down image of the structured and flat surfaces after 10 min of water flow at 100 $\mu \mathrm{L} / \mathrm{min}$. The structured surface appears to retain more lubricant than the flat surface, as indicated by the brighter red color. This is in agreement with the gravimetric data taken from the tubing, which showed more lubricant retention on the structured surfaces than the flat surfaces, as well as with previous results on similar systems under shear applied by spinning in air. ${ }^{25}$

Figure $4 \mathrm{~B}$ shows the change in the amount of lubricant remaining on these surfaces, measured via average red intensity, as water is pumped through the channel at increasing flow rates. There is no drastic drop in the fluorescence intensity coming off the surface, even at the higher flow rates. The calculated shear stress caused by the water flowing over these surfaces was found to be between 0.14 and $2.32 \mathrm{~kg} / \mathrm{m} \cdot \mathrm{s}^{2}$, making the amount of exerted shear stress 1-2 orders of magnitude larger than those tested on the peristaltic pump system (o.01-0.07 $\mathrm{kg} / \mathrm{m} \cdot \mathrm{s}^{2}$ ) (see Supplementary Information Table S1 for details). Although this is an indirect measurement of the presence of the lubricant, it is in agreement with the GCMS and GC-ECD results showing that the lubricant layer is retained under these conditions. 


\section{Structured}

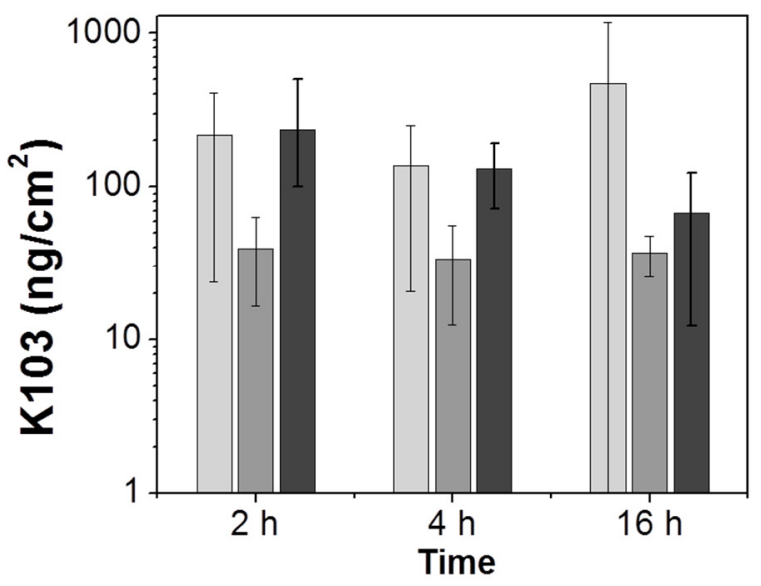

$10 \mathrm{~mL} / \mathrm{min}$

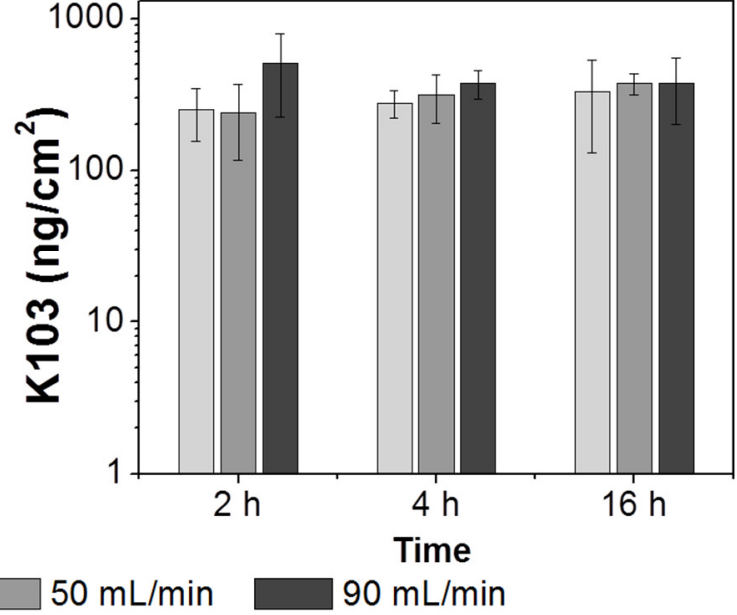

Figure 3. Amount of Krytox 103 lubricant (K103) present in the flow liquid (water) after 2, 4, and $16 \mathrm{~h}$ under flow over structured (left) and flat (right) surfaces. Statistical analysis revealed no significant difference between the two surface types, nor among the flow rates or times measured $(P>0.05)$.

When the flow rate is increased to 800 and 1600 $\mu \mathrm{L} / \mathrm{min}$, there does appear to be a slight decrease in the fluorescence intensity, which may correspond to some of the lubricant being sheared off the surface in this experiment. However, control experiments using either untreated (non-fluorinated) surfaces or fluorinated solvents in place of water as the flow liquid, showed a drop in intensity to nearly zero on the flat surfaces under these conditions (Figures $\mathrm{S}_{3}$ and $\mathrm{S}_{4}$ in the Supplementary Information). The decrease in fluorescence seen in Figure $4 \mathrm{~B}$ is very small in comparison, and a an analogous experiment did not show it to be a consistent occurrence (Figure $S_{5}$ in the Supplementary Information). These small changes can be further seen in Figure ${ }_{4} \mathrm{C}$, which shows a cross-section of the channel at 100 and $1600 \mu \mathrm{L} / \mathrm{min}$. The thickness of the lubricant layer in these images does not change drastically between the low and high flow rates.

Results from the macroscale pump experiments and the mesofluidic channel experiments both confirm that only a trace amount of lubricant is being lost into the bulk water under the flow rates and conditions tested. As discussed in the introduction, previous calculations and experimentation done on the stability of liquid/liquid interfaces have shown a strong dependence on the distance of the interface from a solid wall ${ }^{22,24}$ although only calculated and measured for systems scaled on the order of $\mathrm{mm}$ to $\mathrm{cm}$. Part of the reason for the lack of lubricant loss in our systems may therefore be the close proximity of the tube or channel wall, which is on the order of $\mathrm{nm}$ to $\mu \mathrm{m}$, based on previous studies reporting the lubricant thickness as a function of $\operatorname{shear}^{25}$ as well as the results shown in Figure $4 \mathrm{C}$.

The fact that there is no apparent difference in lubricant loss between the structured and flat surfaces may be somewhat surprising at first glance. Previous work on the retention of Krytox lubricants on various surfaces under shear from spin-coating has shown that a flat, fluorinated, and lubricated silicon wafer loses its low contact angle hysteresis at an rpm of only 3000, indicative of a loss of a confluent lubricant layer. In contrast, nanostructured surfaces similar to those used here retained low contact angle hysteresis values even after spinning at 10,000 rpm. ${ }^{25}$ The difference between these results and what is reported here may be explained by the magnitude of the force. Calculations of the impulse per unit area for the two systems (spin vs. flow) yielded a value 10 to 100 times greater for lubricant-coated surfaces exposed to force by spinning compared to those exposed to force from flow over the surface. Furthermore, the way in which the lubricant was forced from the surface may have played a role. When shear is created via spin, the centrifugal force is applied more or less evenly throughout the thickness of the lubricant layer. This is in contrast to shear created by the flow of a liquid layer over the lubricant, in which the force is only applied to the top layer and must be distributed downward, resulting in less overall force per unit area of lubricant. In addition, since any excess lubricant present on the surfaces was removed during the conditioning step prior to both types of experiments reported here (macroscale and mesoscale), the remaining layer would be indeed expected to be relatively stable. Therefore, the force applied via flow, combined with the relatively low flow rates used in these experiments, may explain why no significant difference between the lubricant loss from the flat and structured surfaces is observed. 


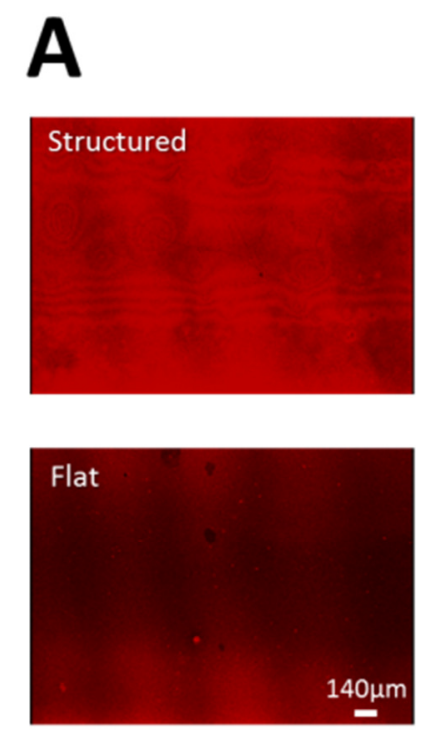

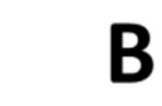

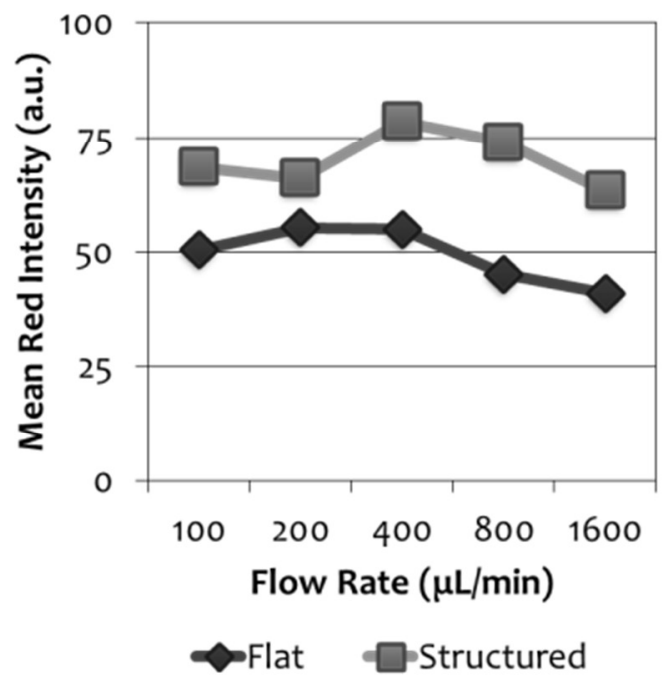

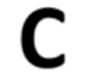
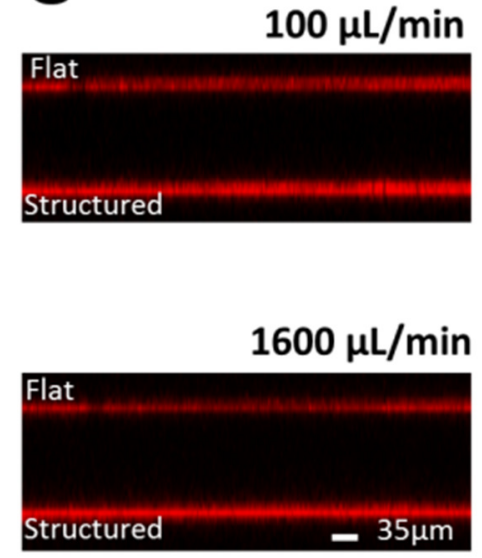

Figure 4. (A) Top-down views of the flat and structured surfaces covered with the dyed fluorescent Krytox 103. (B) Mean red intensity of the flat (diamonds) and structured (squares) surfaces at varying flow rates. (C) Confocal cross-sections of the channels with the flat and structured surfaces indicated at 100 $\mu \mathrm{L} / \mathrm{min}$ (upper image) and $1600 \mu \mathrm{L} / \mathrm{min}$ (lower image).

3.3 Effect of Lubricant Type. The same set of experiments (quantification, visualization) was performed using the lubricant perfluorodecalin (viscosity $2.94 \mathrm{cSt}$ at 25 ${ }^{\circ} \mathrm{C}$ ) in place of Krytox 103 (viscosity $80 \mathrm{cSt}$ at $25^{\circ} \mathrm{C}$ ) to test the effect of lubricant type on loss. Gravimetric analysis showed an initial lubricant retention of $0.04 \mathrm{~g}( \pm 0.02 \mathrm{~g})$ for the structured surfaces and sliding angles of less than $5^{\circ}$ both before and after flow. The flat surfaces showed some areas of dewetting after addition of the lubricant, and as a result retained a more variable amount of perfluorodecalin ( $0.11 \mathrm{~g} \pm 0.04 \mathrm{~g}$ ). The initial sliding angles for this tubing were at or below $5^{\circ}$ in areas where the lubricant layer was confluent, but pinning points were present in dewetted areas. After flow, more pinning points were present giving a sliding angle of $21 \pm 5^{\circ}$. However, lubricant was still visible by eye on the surfaces, unlike nonfluorinated controls which showed no visible lubricant after flow.

GC-MS analysis of the water for perfluorodecalin concentrations after flow also showed very low amounts ( $\mathrm{ng} / \mathrm{cm}^{2}$ range) present in the water after passing over the lubricated surface (Figure 5). There were no significant differences among flow rates or times, nor between surface types or measured solubility under static conditions ( $\mathrm{P}>0.05$, refer to data in Supplementary Info), similar to what was observed in the tubing treated with Krytox 103. However, the results did appear to be more variable than those measured for Krytox 103.

This greater amount of variability in the amount of lubricant removed from perfluorodecalin-lubricated sur- faces as compared to Krytox 103 coated surfaces may be due to the differences in viscosity between the two lubricants ( $2.8 \mathrm{cSt}$ for perfluorodecalin versus $80 \mathrm{cSt}$ for Krytox 103). The lower viscosity of perfluorodecalin would make a lubricant/liquid interface of this material and water more easily deformed than one of Krytox 103/water. Deformations, in turn, can lead to migration of the lubricant on the surface, creation of dewetted islands or entrainment of drops in the flowing water, which can then lead to more variable measurements.

Visual analysis of perfluorodecalin-coated structured and flat surfaces under flow showed less lubricant on the flat surface compared to the structured surface (Figure 6A). This difference was even more pronounced than for the samples coated in Krytox 103 (Figure 4A). Furthermore, the flat surfaces coated with perfluorodecalin appeared to show patches of dewetting, consistent with what had been observed in the tubing with flat surfaces coated with this type of lubricant. As the flow rate increased, the structured surfaces showed a variation in intensity. The flat surfaces appeared to remain somewhat constant throughout the experiment (Figure 6B). Examination of the cross sections of the channels at $100 \mu \mathrm{L} / \mathrm{min}$ and $1600 \mu \mathrm{L} / \mathrm{min}$ (Figure 6C) appeared to show some discontinuity in the lubricant layer at the lower flow rate, which became less pronounced at the higher flow rate. However, a clear lubricant layer was present at all flow rates for both the flat and structured surfaces. This is notable given the relatively high shear stresses applied under these conditions $\left(2.32 \mathrm{~kg} / \mathrm{m} \cdot \mathrm{s}^{2}\right.$ for flow at 1600 $\mu \mathrm{L} / \mathrm{min}$ ) and suggest that the shear conditions under 
which these surfaces would fail are likely very high. The variation in intensity on the surfaces at the different flow rates may indicate a movement of the lubricant around the surface.

\section{Structured}

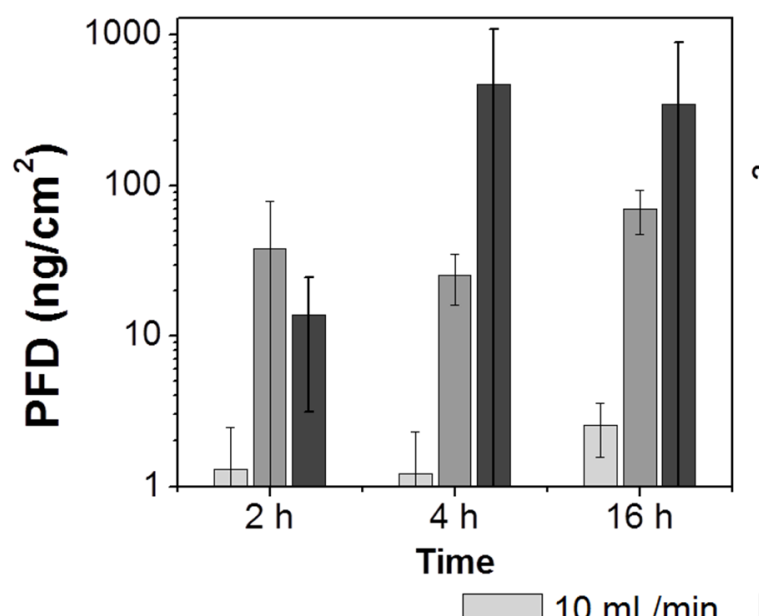

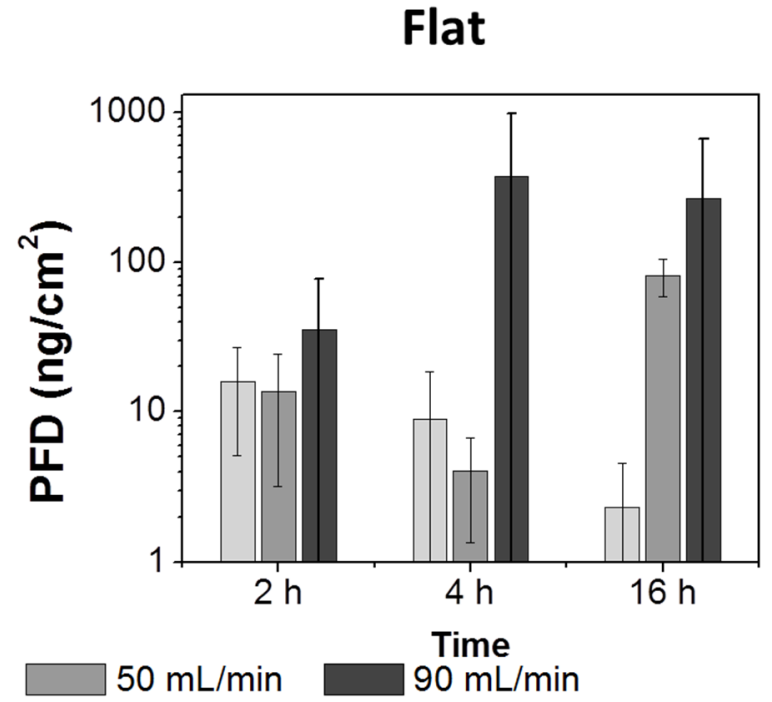

Figure 5. Amount of lubricant present in the flow liquid (water) after 2, 4, and $16 \mathrm{~h}$ under flow over structured (left) and flat (right) surfaces. A univariate ANOVA revealed no significant difference in the amount of lubricant present among the three flow rates, or between the flat and structured surfaces $(P>0.05)$.

The greater difference between the amount of lubricant on the flat versus the structured surfaces for perfluorodecalin compared to the Krytox 103 lubricant used in Figure 4 is not unexpected and may again be due to the difference in viscosity between the two. The less viscous perfluorodecalin lubricant would require less energy to push along the surface and a layer of this type of lubricant would, therefore, be more likely to be thinner after the same amount of time and application of shear force. The capillarity of the nanoscale topography of the structured surface, however, would be expected to retain more of both types of lubricants than the flat surfaces when exposed to shear ${ }^{25}$, which would explain why the fluorescence intensity of the structured surfaces appears brighter when coated with either perfluorodecalin or Krytox 103.

The areas of apparent dewetting on the flat surfaces (Figure 6A) may explain to some extent the presence of pinning observed in the tubing with flat surfaces, especially after $16 \mathrm{~h}$ of flow. No unlubricated patches were observed on the structured surfaces due to the capillary action of the nanostructures that stabilizes the lubricant within the nanostructured pores. The larger lubricant reservoir present on the structured surfaces in comparison to the flat surfaces may have also made it possible for these samples to self-heal the dewetted areas, if they form. ${ }^{1}$ In support of this, control experiments on lubricant retention on flat and structured surfaces with no fluorination did still show a constant amount of lubricant retained on structured surfaces, in contrast to flat surfaces (see Supplemental Information Figure $\mathrm{S}_{4}$ ). However, this could also be due to retention of nanoparticles within the surface structures

3.4 Effect of the Air/Water Interface. Although surface type, flow rate, lubricant type, and time up to $16 \mathrm{~h}$ did not significantly affect the integrity of the lubricant layer under flow, passage of an air/water interface over the surface did. Figure 7 shows a quantification of the total amount of either Krytox 103 or PFD present in water after $16 \mathrm{~h}$ under flow. The first set was collected completely under liquid (i.e. no air/water interface was introduced), while the second set was collected immediately after the first set by passage of an air/water interface over the lubricated surface.

For both Krytox 103 and perfluorodecalin, as well as for both flat and structured surfaces, the total amount of lubricant present in water before passage of the air/water interface is in the single $\mu \mathrm{g}$ scale, while subsequent introduction of an air/water interface to the same surface results in an increase in the amount of lubricant removed by 1-2 orders of magnitude (up to tens of $\mu \mathrm{g}$, see Figure 7 ). It should be noted that these results were found to be highly dependent on the number of air/water interfaces that passed over the surface as well as the shape of the interface: only those with single, clean air/water interfaces passages are shown here. Even with this limitation, the amount of lubricant removed was highly variable. 

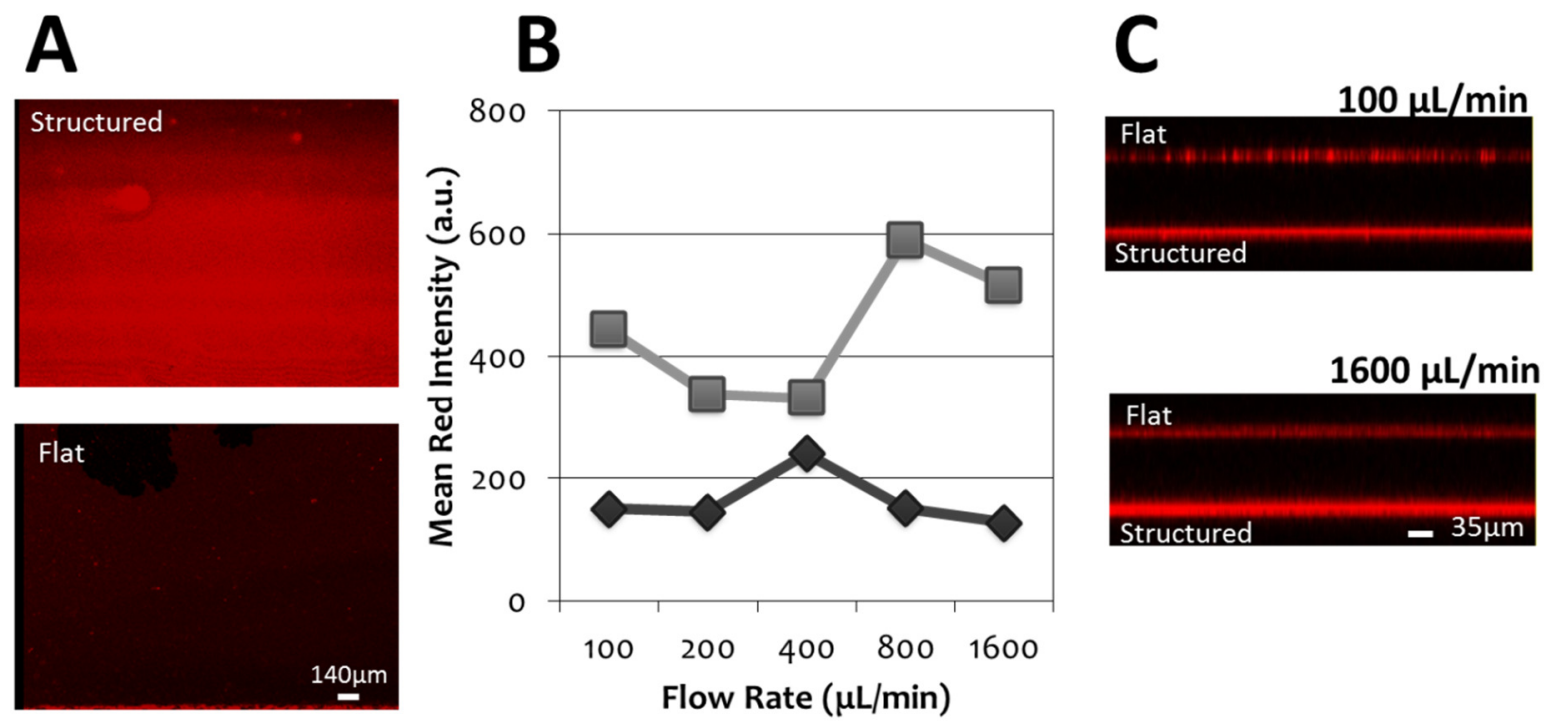

$\curvearrowright$ Flat $\square$ Structured

Figure 6. (A) Top-down views of the flat and structured surfaces covered with the dyed fluorescent perfluorodecalin and exposed to water flow at $100 \mu \mathrm{L} / \mathrm{min}$ for $10 \mathrm{~min}$. (B) Mean red intensity of the flat (diamonds) and structured (squares) surfaces at varying flow rates. C) Confocal cross-sections of the channels with the flat and structured surfaces indicated at $100 \mu \mathrm{L} / \mathrm{min}$ (upper image) and $1600 \mu \mathrm{L} / \mathrm{min}$ (lower image

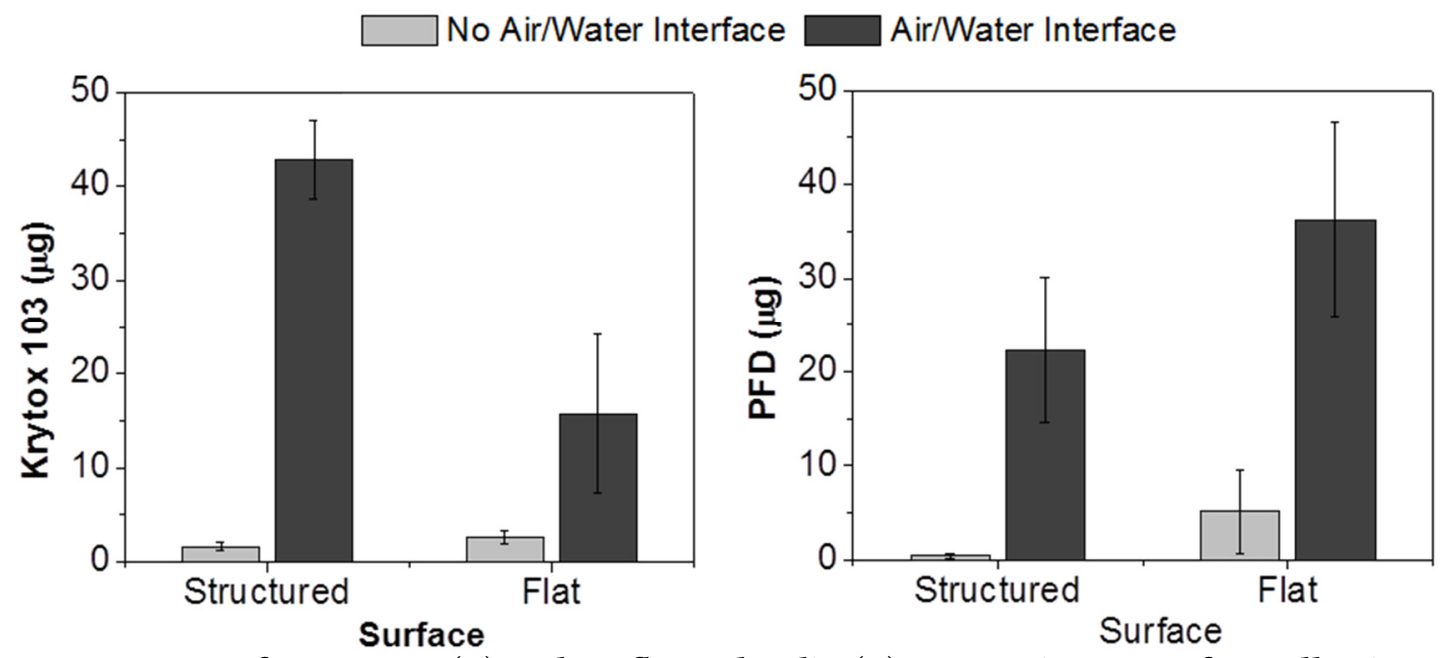

Figure 7. Amount of Krytox 103 (A) and perfluorodecalin (B) present in water after collection without passing an air/water interface over the structured (dark bars) and flat (light bars) tubing surfaces, then passing a single air/water interface over the tubing surfaces directly afterward. The passage of the air/water interface significantly increases the amount of lubricant present in the water in all cases $(\mathrm{P}<$ 0.05).

The increase in lubricant loss from the surface with passage of the air/water interface is logical given the known tendency of these low-surface-energy liquids to form a wrapping layer over single water droplets in air. ${ }^{26,27}$ If this happens while the drop is in motion, it will carry away the lubricant covering it, effectively stripping that amount of lubricant from the surface. This effect was visualized using the mesoscopic channels and fluorescent lubricant. Figure 8 shows a schematic and a series of topdown images of a mesofluidic channel as an air/water interface passes through. A concentration of fluorescent lubricant can be seen at interface. 

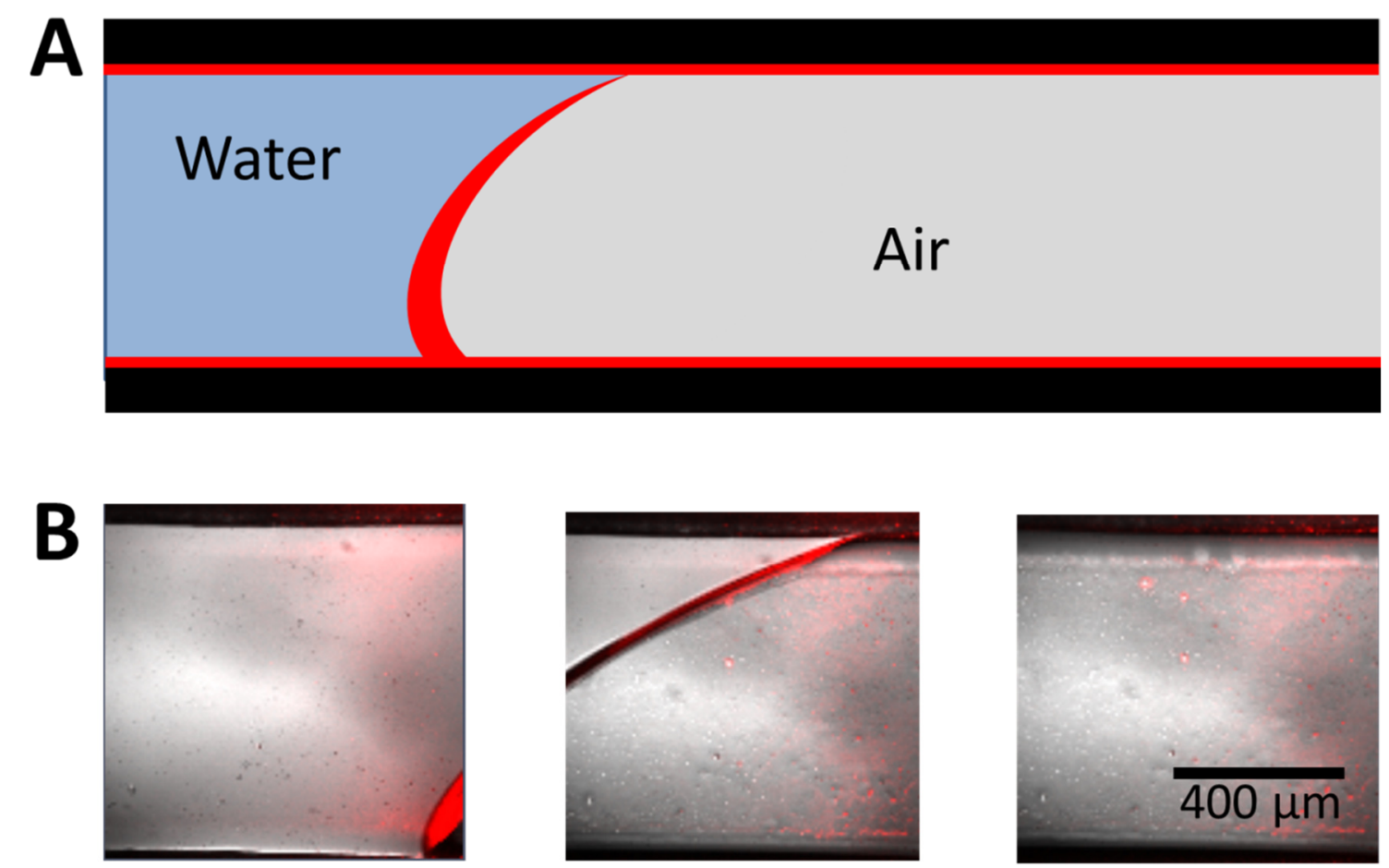

Figure 8. Schematic (A) and composite fluorescent- light microscopy image (B) of a microchannel as the air/water interface passes (top-down view). The interface shows a distinct coating of the lubricant, as would be expected due to the formation of a wrapping layer.

The effect that the air/water interface has on both flat and structured surfaces coated in Krytox 103 can be seen in Figure 9. Both surface types are affected by the passage, losing both fluorescence intensity as well as layer continuity. However, the structured surface appears to retain a more even layer than the flat surface. This observation is in agreement with the sliding angle results found in the pump-flow experiments using Krytox 103. After $16 \mathrm{~h}$ of flow in the coated tubing, followed by the necessary passage of the air/water interface to remove the liquid, the sliding angles of the structured surface remained consistently below $5^{0}$ while for the flat surfaces they became on average higher and more variable $\left(12^{\circ} \pm 6^{\circ}\right)$.

The ability of the structured surfaces to retain more lubricant under flow than the flat surfaces (as seen in Figures 4 and 6) may explain the apparently greater disruption of the lubricant layer on the latter. If a thicker lubricant layer is initially present, such as what was observed on the structured surfaces, then more lubricant will remain on the surface after the air/water interface has passed to continue to provide slippery functionality.

\section{CONCLUSIONS}

We have investigated lubricant loss from surfaceimmobilized lubricant layers under flow using a combination of gas chromatography to quantify the amount of lubricant in the flow liquid (water in a closed loop) and confocal microscopy to visualize lubricant retention. We have tested both nanostructured, fluorinated and flat, fluorinated surfaces over a range of physiologically- relevant flow rates for up to $16 \mathrm{~h}$ and compared them to the unfunctionalized controls. Furthermore, we have examined these systems coated with two types of lubricants (Krytox 103 and perfluorodecalin) with differing viscosities.

We find no significant differences in lubricant loss between fluorinated structured and flat surfaces under any of the conditions tested (flow rate, time, lubricant type). Instead, all surface types, flow rates, times, and lubricant types yielded lubricant losses into the water on the order of ng per $\mathrm{cm}^{2}$ of the inner coated surface, roughly equivalent to what was observed for static diffusion due to the intrinsic solubility of the lubricant. These quantitative results were confirmed with visualization experiments, which showed no continuous losses of fluorescently-labeled lubricant with increasing flow rates through mesofluidic channels (although variation in the amount of lubricant on the surfaces was observed, especially for the low-viscosity perfluorodecalin). Furthermore, the insignificant difference between the structured and flat surfaces suggests that we are indeed measuring lubricant loss from just the lubricant/water interface, as flat surfaces are expected to have less overall lubricant than structured surfaces, ${ }^{25}$ and would therefore be expected to show less lubricant loss overall if all the lubricant were being stripped away from the surfaces. 


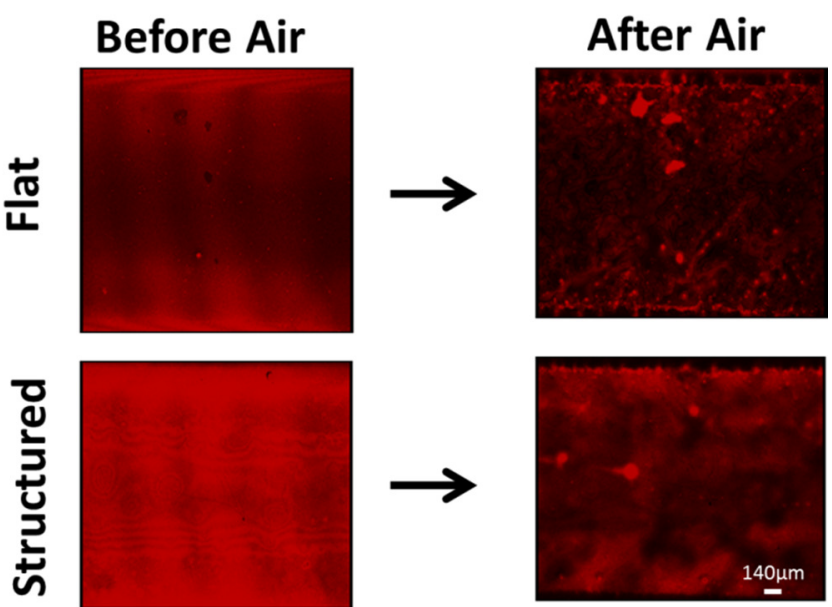

Figure 9. Top-down views of the flat and structured surfaces coated with Krytox 103 before and after passage of the air/water interface.

Altogether, these results demonstrate that the surface-stabilized lubricant/liquid layers tested are stable under the physiologically-relevant flow conditions used in these experiments. Furthermore, no stripping of the lubricant layer was observed when shear stresses were increased up to This included qualitative results up to $\mathbf{2 . 3 2}$ $\mathrm{kg} / \mathrm{m} \cdot \mathrm{s}^{2}$, suggesting that the shear stresses at which these layers fail will likely be quite high. Determination of exactly when they fail will be an important next step, and especially useful for many industrial applications.

Nevertheless, it was observed that this stability was highly dependent on keeping the surfaces under liquid, with any passage of an air/water interface over the lubricant layers resulting in a significant increase of the amount of lubricant removed from the surface. This was attributed to the formation of a lubricant wrapping layer at the air/water interface, which would then carry the volume of wrapping lubricant away. This resulted in a decreased amount of lubricant on the surfaces, and in cases where less lubricant was present an extensive disruption of the continuous layer.

The systems studied here use fluorinated surfaces and fluorinated lubricants. However, other types of lubricants do exist that can satisfy the desired surfaces energy relationship between lubricant/air, lubricant/water, and water/air for which the formation of the wrapping layer becomes unfavorable (and therefore substantially less pronounced). The selection of such lubricants for a SLIPS system should result in a significantly increased longevity in the face of air/water interfaces, and should therefore be considered for applications in which these conditions will be present. It is important to note that the experiments presented here were only performed over a certain range of relatively low flow rates. At much higher rates, the effects observed are likely to be even more pronounced or may be different.

\section{ASSOCIATED CONTENT}

Supporting Information. Shear stress calculations, XPS surface analysis, lubricant solubility measurements, validation of confocal measurements with lubricant dye. This material is available free of charge via the Internet at http://pubs.acs.org.

\section{AUTHOR INFORMATION \\ Corresponding Authors}

*Caitlin Howell: chowell@seas.harvard.edu; *Joanna Aizenberg: jaiz@seas.harvard.edu

Present Addresses

†Leslie Dan Faculty of Pharmacy, University of Toronto, Toronto, ON, Canada

\section{Author Contributions}

The manuscript was written through contributions of all authors.

\section{Notes}

The authors declare no competing financial interest.

\section{ACKNOWLEDGMENT}

The authors thank Andreas Carlson for helpful advice and Haylea Ledoux with technical assistance. This material is based upon work supported by the Defense Advanced Research Projects Agency grant N66oo1-11-1-418o and contract HRoo11-13-C-0025, as well as by the Office of Naval Research under Award Number N-oooo14-12-1-0962 to Princeton University. This work was performed in part at the Center for Nanoscale Systems (CNS), a member of the National Nanotechnology Infrastructure Network (NNIN), which is supported by the National Science Foundation under NSF award no. ECS-0335765. CNS is part of Harvard University.

\section{REFERENCES}

(1) Wong, T.-S.; Kang, S. H.; Tang, S. K. Y.; Smythe, E. J.; Hatton, B. D.; Grinthal, A.; Aizenberg, J. Nature 2011, 477, 443-447.

(2) Leslie, D. C.; Waterhouse, A.; Berthet, J. B.; Valentin, T. M.; Watters, A. L.; Jain, A.; Kim, P.; Hatton, B. D.; Nedder, A.; Mullen, K.; Super, E. H.; Howell, C.; Johnson, C. P.; Vu, T. L.; Rifai, S.; Hansen, A.; Aizenberg, M.; Super, M.; Aizenberg, J.; Ingber, D. E. Nat. Biotechnol. 2014, 32, 1134-1140.

(3) Kim, P.; Wong, T.-S.; Alvarenga, J.; Kreder, M. J.; Adorno-Martinez, W. E.; Aizenberg, J. ACS Nano 2012, 6, 6569-6577.

(4) Howell, C.; Vu, T. L.; Lin, J. J.; Kolle, S.; Juthani, N.; Watson, E.; Weaver, J. C.; Alvarenga, J.; Aizenberg, J. ACS Appl. Mater. Interfaces 2014, 6, 13299-13307. 
(5) Epstein, A. K.; Wong, T.-S.; Belisle, R. a; Boggs, E. M.; Aizenberg, J. Proc. Natl. Acad. Sci. U. S. A. 2012, 1-6.

(6) Li, J.; Kleintschek, T.; Rieder, A.; Cheng, Y.; Baumbach, T.; Obst, U.; Schwartz, T.; Levkin, P. A. ACS Appl. Mater. Interfaces 2013, 5, 67046711.

(7) MacCallum, N.; Howell, C.; Kim, P.; Sun, D.; Friedlander, R.; Ranisau, J.; Ahanotu, O.; Lin, J. J.; Vena, A.; Hatton, B.; Wong, T.; Aizenberg, J. ACS Biomater. Sci. Eng. 2015, 1, 43-51.

(8) Xiao, L.; Li, J.; Mieszkin, S.; Di Fino, A.; Clare, A. S.; Callow, M. E.; Callow, J. a; Grunze, M.; Rosenhahn, A.; Levkin, P. a. ACS Appl. Mater. Interfaces 2013, 5, 10074-10080.

(9) Arnott, J.; Wu, A. H. F.; Vucko, M. J.; Lamb, R. N. Biofouling 2014, 30, 37-41.

(10) Hoipkemeier-Wilson, L.; Schumacher, J. F.; Carman, M. L.; Gibson, A. L.; Feinberg, A. W.; Callow, M. E.; Finlay, J. a; Callow, J. a; Brennan, A. B. Biofouling 2004, 20, 53-63.

(11) Vogel, N.; Belisle, R. a; Hatton, B.; Wong, T.-S.; Aizenberg, J. Nat. Commun. 2013, 4, 2167.

(12) Yao, X.; Hu, Y.; Grinthal, A.; Wong, T.-S.; Mahadevan, L.; Aizenberg, J. Nat. Mater. 2013, $12,529-534$.

(13) Statz, A. R.; Meagher, R. J.; Barron, A. E.; Messersmith, P. B. J. Am. Chem. Soc. 2005, 127, 7972-7973.

(14) Deng, L.; Mrksich, M.; Whitesides, G. M. J. Am. Chem. Soc. 1996, 118, 5136-5137.

(15) Zhou, Z.; Calabrese, D. R.; Taylor, W.; Finlay, J. a; Callow, M. E.; Callow, J. a; Fischer, D.; Kramer, E. J.; Ober, C. K. Biofouling 2014, 30, 589-604.

(16) Park, K.-C.; Choi, H. J.; Chang, C.-H.; Cohen, R. E.; McKinley, G. H.; Barbastathis, G. ACS Nano 2012, 6, 3789-3799.

(17) Pan, S.; Kota, A. K.; Mabry, J. M.; Tuteja, A. J. Am. Chem. Soc. 2013, 135, 578-581.
(18) Tuteja, A.; Choi, W.; Ma, M.; Mabry, J. M.; Mazzella, S. A.; Rutledge, G. C.; McKinley, G. H.; Cohen, R. E. Science (80-. ). 2007, 318, 16181622.

(19) Wal, P. van der; Steiner, U. Soft Matter 2007, 3, 426-429.

(20) Barthlott, W.; Neinhuis, C. Planta 1997, 202, 18.

(21) Qu r, D.; Lafuma, A. L.; Bico, J. Nanotechnology 2003, 14, 1109-1112.

(22) Ooms, G. Fluid-mechanical studies on coreannular flow, Delft University of Technology, 1971, p. 83.

(23) Bannwart, A. C. J. Pet. Sci. Eng. 2001, 32, 127143.

(24) Asiegubu, C. P.; Asakura, K. J. Solid Mech. Mater. Eng. 2008, 2, 831-841.

(25) Kim, P.; Kreder, M. J.; Alvarenga, J.; Aizenberg, J. Nano Lett. 2013, 13, 1793-1799.

(26) Smith, J. D.; Dhiman, R.; Anand, S.; RezaGarduno, E.; Cohen, R. E.; McKinley, G. H.; Varanasi, K. K. Soft Matter 2013, 9, 1772.

(27) Carlson, a.; Kim, P.; Amberg, G.; Stone, H. a. EPL (Europhysics Lett. 2013, 104, 34008.

(28) Daniel, D.; Mankin, M. N.; Belisle, R. a.; Wong, T.-S.; Aizenberg, J. Appl. Phys. Lett. 2013, 102, 231603.

(29) Wilson, P. W.; Lu, W.; Xu, H.; Kim, P.; Kreder, M. J.; Alvarenga, J.; Aizenberg, J. Phys. Chem. Chem. Phys. 2013, 15, 581-585.

(30) Lowe, K. C. Comp. Biochem. Physiol. A 1987, 87, $825-838$.

(31) Holloway, G. M.; O’Rear, E. A.; Fung, B. M. Blood 1986, 67, 173-176.

(32) Winter, M.; Winter, C.; Wiechens, B. Graefe's Arch. Clin. Exp. Ophthalmol. 1999, 237, 153-156.

(33) Peyman, G. A.; Schulman, J. A.; Sullivan, B. Surv. Opthalmology 1995, 39. 
（34） Coulthard, M. G.; Crosier, J.; Griffiths, C.; Smith, J.; Drinnan, M.; Whitaker, M.; Beckwith, R.; Matthews, J. N. S.; Flecknell, P.; Lambert, H. J. Pediatr. Nephrol. 2014, 29, 1873-1881.

(35) Orimi, S.; Minzuno, K.; Narahara, M.; Umakosi, H.; Kaihara, M.; Hasimoto, M. Ther. Apher.

Dial. 2011, 15, 1744-9987.

(36) Zar, J. H. Biostatistical Analysis; 4th Editio.; Prentice Hall: Upper Saddle River, NJ, 1993; p. 279. 
Table of Contents artwork
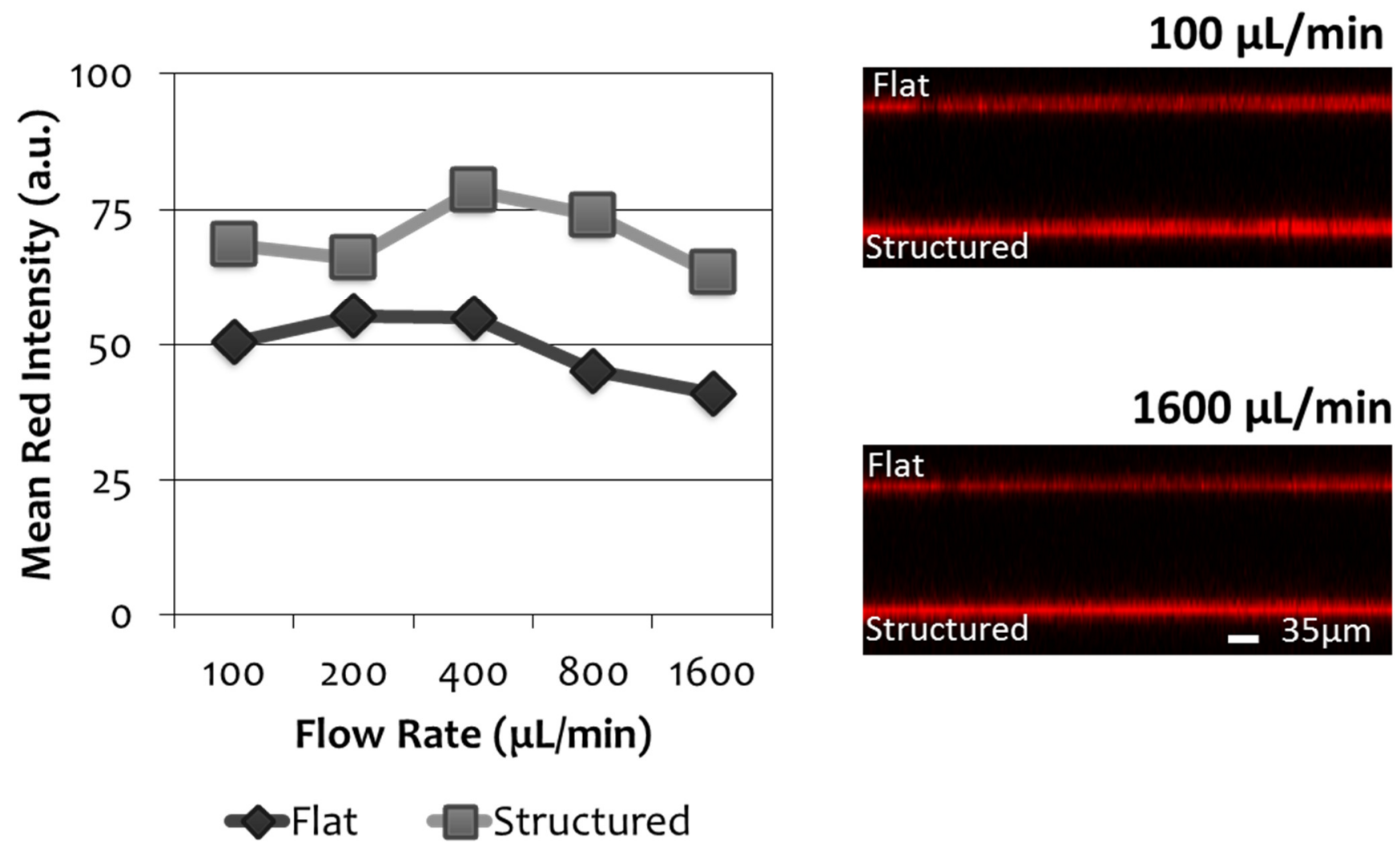